\title{
Simulation of Direct Torque Control for Five-Phase PMSM and Comparison of Optimized Vector Tables
}

\author{
Gang Zhao \\ College of Transportation \\ Shandong University of Science and \\ Technology \\ Qingdao, China \\ 47994337@qq.com
}

Hongliang Zhao

College of Electrical Engineering and Automation

Shandong University of Science and

Technology

Qingdao, China

zh16401@126.com

\author{
Haiying Liu \\ College of Transportation \\ Shandong University of Science and \\ Technology \\ Qingdao, China \\ eliuhaiying@163.com \\ Yikun Yuan \\ College of Electrical Engineering and \\ Automation \\ Shandong University of Science and \\ Technology \\ Qingdao, China \\ yyk02@163.com
}

\author{
Fangyi Zhang \\ College of Transportation \\ Shandong University of Science and \\ Technology \\ Qingdao, China \\ 240094417@qq.com \\ Yongchang Jiang \\ College of Mechanical and Electronic \\ Engineering \\ Shandong University of Science and \\ Technology \\ Qingdao, China \\ $1312369905 @ q q . c o m$
}

\begin{abstract}
In this paper a simulation of direct torque control for five-phase PM motor has been designed. The modeling of Five-phase PMSM is based on three-phase PMSM..The prototyping platform system uses Matlab/Simulink. A graphical programming interface with hardware-in-loop design process for testing the algorithms is used. Compared with three-phase PM motor, this paper presents the mathematical model of five-phase PM motor, The designed direct torque control is simulated in Matlab/Simulink environment. From simulating, the five-phase PM motor can be controlled well. But there is a large torque ripple. Moreover a modified space voltage vector section table is presented, and the torque ripples are reduced.
\end{abstract}

Keywords-five-phase PM motor, direct torque control, graphical programming, torque ripples

\section{INTRODUCTION}

The Permanent Magnet Synchronous motors are being used in place of conventional dc motors in recent years. These motor have special features like high efficiency, and high power density. However, the multiphase motor have been more and more popular in industrial applications and scientific research. The multiphase systems have more advantages compared to the three-phase motor like high output power rating, less harmonics in the dc link current and low torque pulsation and stable speed response. At present multiphase drive, system have gained increasing demand owing to their performance and stable operation even when load fluctuations occur. Also, Multi-phase motor drives posses more advantages than the conventional threephase motor drives such as

(1)Reducing the amplitude and increasing the frequency of torque pulsation.

(2)Reducing the stator current per phase without increasing the voltage per phase.

(3)Increasing the reliability and power density.
(4)Increasing the torque producing capability of the motor.

(5)Adjusting of the torque and flux linkage of the fivephase direct torque controlled system in a better ways[1].

It is well known that DTC can control the motors well. In the static coordinate, through controlling flux linkage and torque, let the flux linkage's trajectory be a circle to complete motor's sustainable rotation[2].

It has been show by literature that the matlab/simulink is a convenient and effective tool to simulate the process of control. In[3], the embedded motor drive prototype platform is presented, it introduces the prototyping platform uses Matlab/simulink and target support package for TI C2000 toolbox. Also presents the process of automatic code generation under Matlab/simulink and compose studio from TI. So it has powerful functions and concise graphical programming interface[4].Many studies have analyzed the control strategy of three-phase PM motor. In[5], it presents clearly that three-phase PM motors' control and simulation. Among them, FOC and DTC have been get widely use. Nevertheless, DTC is based on the static coordinate, due to the advantage of rapid dynamic torque respond, concise control structure and better robust control, more and more scholars and research units started focus on the area[6].As for five-phase PM motor, in[7],the paper proposes the application of LQR for for five-phase PMSM, it also simulated in Matlab/Simulink environment. In[8], it presents the modeling and simulation of five-phase induction motor. Through the clarke transformation, it can be analyze in the $\alpha-\beta$ plane and has similar dynamic features. In[9], it also presents that in the $\alpha-\beta$ plane, five-phase induction motor is similar with three-phase induction motor.

In this paper, five-phase PMSM mathematical model is developed based on the three-phase PMSM. It gives the concise mathematical expression. The control strategy adopted DTC, according to the DTC for three-phase PMSM, 
it presents space vector selection table in five-phase motors' control. through adopting the most simple method, the motor can be controlled well. The results prove that the method is available.

The paper is organized as follows. The mathematical model of Five-phase PMSM is presented in first part of section 2.In section 3 ,it presents the space vector selection table and simplified PWM model of five-phase PMSM, in same section the principle of DTC is presented. In section 4 ,the simulation in Matlab/simulink environment is done. All the part of control structure is presents. Through changing the control parameter, it has different control results. In section 5,a modified space voltage vector selection table is presented to reduce the torque ripples. The paper ends with conclusion.

\section{MATHEMATICAL MODELING OF FIVE-PHASE PMSM}

Due to the convenience and concision in $d-q$ axis, it needs transformed the a-b-c-d-e axis plane to the d-q axis plane using clarke and park transformation. Comparing the three-phase PMSM model, it can get relation of each coordinate. As shown in Fig.1.

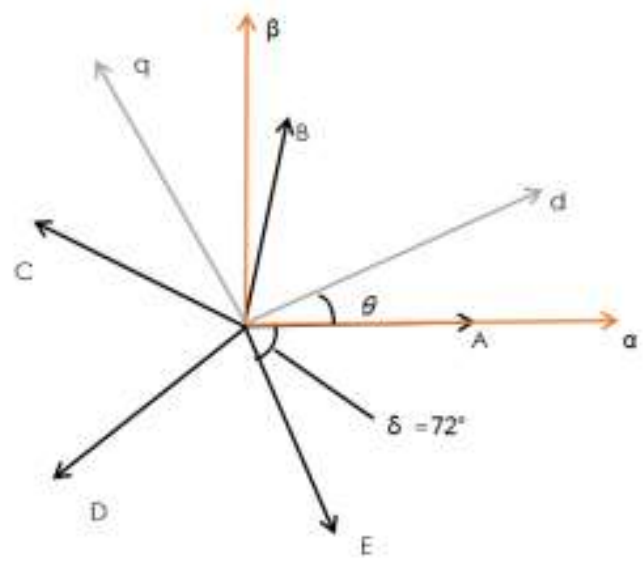

Fig.1 The relation of three kind of coordinates

In order to guarantee the amplitude of current is same, the coefficient of clarke transformation is $2 / 5$. So the clarke transformation by the following:

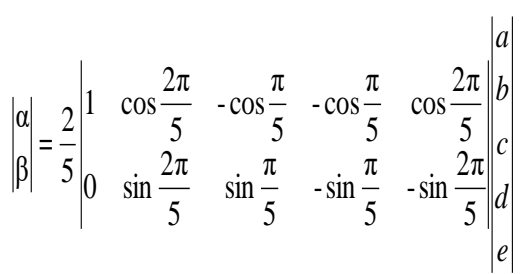

And the park transformation can be written as(2):

$$
\left|\begin{array}{l}
d \\
q
\end{array}\right|=\left|\begin{array}{cc}
\cos \theta & \sin \theta \\
-\sin \theta & \cos \theta
\end{array}\right| \begin{array}{|c}
\alpha \\
\beta
\end{array} \mid
$$

Consequently, the final transformation from a-b-c-d-e plane to d-q plane can be written as(3): $|q|=\left|\begin{array}{ccccc}\cos \theta & \cos \left(\theta-\frac{2 \pi}{5}\right) & \cos \left(\theta-\frac{4 \pi}{5}\right) & \cos \left(\theta+\frac{4 \pi}{5}\right) & \cos \left(\theta+\frac{2 \pi}{5}\right) \\ -\sin \theta & -\sin \left(\theta-\frac{2 \pi}{5}\right) & \sin \left(\theta+\frac{\pi}{5}\right) & \sin \left(\theta-\frac{\pi}{5}\right) & -\sin \left(\theta+\frac{2 \pi}{5}\right)\end{array}\right| \begin{gathered}a \\ b \\ c \\ d \\ e\end{gathered} \mid$

In the type:

a,b,c,d,e are the five-phase stationary reference frame; $\alpha, \beta$ are the two-phase stationary reference frame; $d, q$ are the two-phase rotor reference frame; $\theta$ is the angle between a phase and d phase.

In $d-q$ axis plane, the dynamic equations of a five-phase PMSM are similar to the three-phase PMSM, these are expressed in rotor reference frame theory as given below:

$\frac{d}{d t} i d=\frac{u d}{l d}-r \frac{i d}{l d}+\frac{l q \times p \times w r \times i q}{l d}$

$\frac{d}{d t} i q=\frac{u q}{l q}-\frac{r \times i q}{l q}-\frac{l d \times p \times w r \times i d}{l q}-\frac{\Psi_{f} \times p \times w r}{l q}$

$t e=2.5 \times p \times\left[\psi_{f} \times l q+(l d-l q) \times l d \times l q\right]$

$\frac{d}{d t} w r=\frac{t e-D \times w r-t l}{J}$

$\frac{d}{d t} \theta=p \times w r$

In the type:

id and iq are the components of d-q axis currents;

$\mathrm{ld}$ and $\mathrm{lq}$ are the $\mathrm{d}$ and $\mathrm{q}$ axis inductances;

$\mathrm{ud}$ and $\mathrm{uq}$ are the components of $\mathrm{d}-\mathrm{q}$ axis voltages;

$w r$ is angular velocity of the rotor;

$\mathrm{p}$ is number of pole pairs;

te is the electromagnetic torque;

$r$ is the resistance of stator windings;

$\Psi f$ is the rotor flux linkage vector;

$\mathrm{D}$ is the damping coefficient;

$\theta$ is rotor position at electrical angle;

$\mathrm{t}$ is the load torque;

$\mathbf{J}$ is the combined inertia of rotor and load.

According to these equations, the simulate modeling of five-phase PMSM can be easily established.

\section{THE PRINCIPLE OF DTC AND THE SIMPLE SPACE VECTOR SELECTION TABLE}

DTC was developed in the 1980s.It is a kind of highperformance dynamic AC motor VVVF technology after FOC. Its principle of control is based on the voltage space vector outputting from the VSI. And the stator magnetic field and torque are controlled by the voltage space vector. Due to the(9)(10):

$$
\begin{aligned}
& u=\frac{d}{d t} \Psi \\
& \Psi_{1}=\int_{t}^{t 1} u_{1} d t+\Psi_{1}\left(t_{0}\right)
\end{aligned}
$$

It can be easily control the flux linkage, keeping the stator magnetic field in constant. When the input voltage $\mathrm{u} 1$ is zero vector, the stator flux linkage is the same as before change. So $\Psi 1(\mathrm{t} 1)=\Psi 2(\mathrm{t} 0)$; if $\mathrm{u} 1$ is a nonzero vector, and the flux linkage moving along the direction parallel to the vector $\mathrm{u} 1$ based on the original $\Psi 1(\mathrm{t} 0)$. So choice proper voltage vector in different times, the stator flux linkage can be controlled according to the predetermined trajectory. It can got rotating stator magnetic field easily. 


\section{A. Space voltage vector selection table}

According to the principle of two-level VSI, as for fivephase PMSM system, it can get 32 space voltage vector, This paper only consider the most basic situation. Compared to the three-phase VSI, the space sector can be divided as follow:

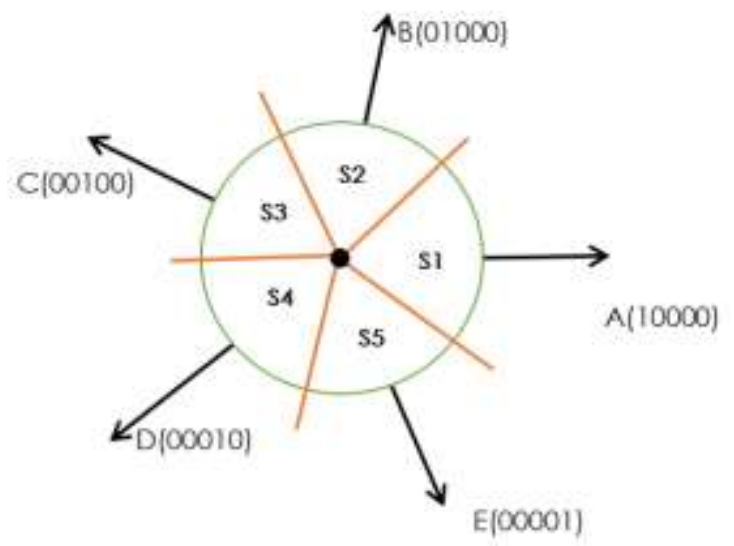

Fig.2 Partition of space sector

When the flux linkage is located in the sector1,the different voltage vector acts on the flux linkage, it can get different influence. The table of influence feature is presented as follow:

Table1 Influence feature in sector1

\begin{tabular}{|l|c|c|c|c|}
\hline classification & U1 & U2 & U3 & U4 \\
\hline $\begin{array}{l}\text { Amplitude } \\
\text { of stator flux } \\
\text { linkage }\end{array}$ & $\uparrow \uparrow$ & $\uparrow$ & $\downarrow$ & $\downarrow$ \\
\hline $\begin{array}{l}\text { Phase angle } \\
\text { of flux } \\
\text { linkage }\end{array}$ & $\begin{array}{r}\text { basically } \\
\text { unchanged }\end{array}$ & $\uparrow$ & $\uparrow$ & $\downarrow$ \\
\hline
\end{tabular}

Where: U1,U2,U3,U4,U5respectively represent the a,b,c,d,e phase space voltage vector.

U1(10000),U2(01000),U3(00100),U4(00010),U5(00001) $; \uparrow$ represent increase; $\uparrow \uparrow$ represent rapid increase; $\downarrow$ represent decrease.

Same argument, it can get influence table in other sectors.

The control objects are stator flux linkage and torque. According to the situation of torque and stator flux linkage's amplitude, it can choice different space voltage vector. The choice table is presented as follow

Table2 Voltage vector selection table

\begin{tabular}{|c|c|c|c|c|c|c|}
\hline \multirow{2}{*}{\multicolumn{2}{|c|}{ classification }} & \multicolumn{5}{|c|}{ flux linkage position } \\
\hline & & s1 & s2 & s3 & s4 & s5 \\
\hline \multirow{3}{*}{$\begin{array}{l}\text { situation } \\
\text { of torque } \\
\text { and stator } \\
\text { flux } \\
\text { linkage's } \\
\text { amplitude }\end{array}$} & $\begin{array}{c}\text { large } \\
\text { flux } \\
\text { linkage, } \\
\text { large } \\
\text { torque }\end{array}$ & U4 & U5 & U1 & $\mathrm{U} 2$ & U3 \\
\hline & $\begin{array}{c}\text { small } \\
\text { flux } \\
\text { linkage, } \\
\text { large } \\
\text { torque }\end{array}$ & U5 & U1 & $\mathrm{U} 2$ & U3 & U4 \\
\hline & $\begin{array}{l}\text { large } \\
\text { flux }\end{array}$ & U3 & U4 & U5 & U1 & $\mathrm{U} 2$ \\
\hline
\end{tabular}

\begin{tabular}{|l|c|l|l|l|l|l|}
\hline & $\begin{array}{c}\text { linkage, } \\
\text { small } \\
\text { torque }\end{array}$ & & & & \\
\cline { 2 - 6 } & $\begin{array}{c}\text { small } \\
\text { flux } \\
\text { linkage, } \\
\text { small } \\
\text { torque }\end{array}$ & $\mathrm{U} 2$ & $\mathrm{U} 3$ & $\mathrm{U} 4$ & $\mathrm{U} 5$ & $\mathrm{U} 1$ \\
\hline
\end{tabular}

\section{B. Estimation of stator flux linkage}

In DTC system, estimation of stator flux linkage is important. There are many methods to estimate the amplitude stator flux linkage, this paper adopts the basic voltage model method.

Same as induction motor, it can estimate stator flux linkage from stator voltage vector equation by:

$$
\Psi_{s}=\int\left(u_{s}-r_{s} \times i_{s}\right) d t
$$

Trough decomposing the $\Psi$ s to the $\alpha-\beta$ static coordinate, adopting $\Psi \alpha$ and $\Psi \beta$ to estimate its amplitude and space phase. The following equations can calculate the flux linkage:

$$
\begin{aligned}
& \psi_{\alpha}=\int\left(u_{\alpha}-r_{s} \times i_{\alpha}\right) d t \\
& \psi_{\beta}=\int\left(u_{\beta}-r_{s} \times i_{\beta}\right) d t \\
& \psi=\sqrt{\psi_{\alpha}^{2}+\psi_{\beta}^{2}} \\
& \theta=\arctan \frac{\psi_{\beta}}{\psi_{\alpha}}
\end{aligned}
$$

\section{SIMULINK MODELING OF FIVE-PHASE PMSM CONTROL SYSTEM}

Simulations are carried out by using Simulink environment in Matlab as the simulation tool to validate the performance of five-phase PMSM using DTC. Tab.3show the parameters of the motor modeling.

Table3 Motor parameters

\begin{tabular}{|c|c|c|}
\hline Symbo & Description & Value \\
\hline$\Psi f$ & $\begin{array}{c}\text { fundamental PM } \\
\text { flux linkage }\end{array}$ & $0.175 \mathrm{~Wb}$ \\
\hline $\mathrm{Ld}$ & d-axis inductance & $8.5 \mathrm{mH}$ \\
\hline $\mathrm{Lq}$ & q-axis inductance & $8.5 \mathrm{mH}$ \\
\hline $\mathrm{p}$ & pole pairs & 4 \\
\hline $\mathrm{J}$ & $\begin{array}{c}\text { combined inertia of } \\
\text { rotor and load. }\end{array}$ & $0.8 \mathrm{e}-3 \mathrm{~kg} \cdot \mathrm{m}^{\wedge} 2$ \\
\hline $\mathrm{R}$ & $\begin{array}{c}\text { resistance of stator } \\
\text { windings }\end{array}$ & $2.875 \Omega$ \\
\hline
\end{tabular}

Also,Fig. 3 presents the detailed simulink model for DTC system.

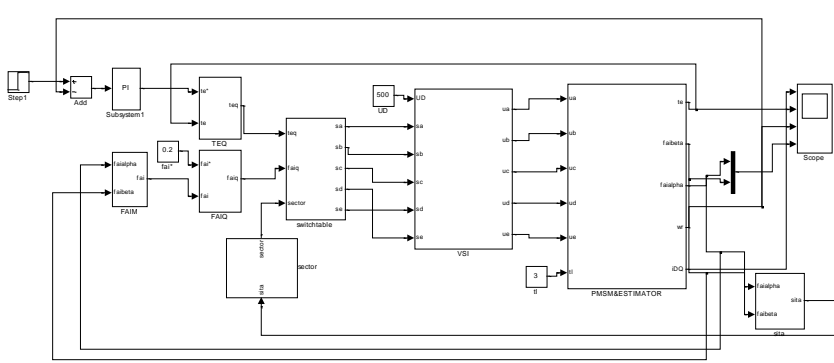

Fig.3.Simulink model for DTC general drawing 
In this simulation, the rotor speed fixed in advance is from 30 to 200 at $t=0.1 \mathrm{~s}$. And the load torque is constant with $3 \mathrm{~N}^{*} \mathrm{~m}$. DC is $500 \mathrm{~V}$.Fig.4shows the simulation results about each physical quantity.

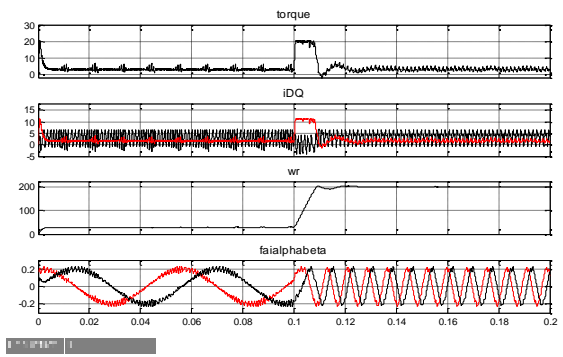

Fig.4. Each physical quantity tendency chart

From Fig.4,where the first frame is torque, the second frame is idq, the third frame is rotor speed, and the last frame is $\Psi \alpha \beta$. PMSM starting with maximum torque at $20 \mathrm{~N}^{*} \mathrm{~m}$, the response of torque is rapidly and the motor starts fast. When the time is about $0.005 \mathrm{~s}$, the speed to the target speed at 30rad/s, then the speed keep stable and the electromagnetic torque is also steady, the same as load torque. When the time is $0.1 \mathrm{~s}$,speed command changes and become $200 \mathrm{rad} / \mathrm{s}$. It can be seen that the electromagnetic torque braking the motor with maximum brake torque at $20 N^{*} m$. The response of motor speed is rapidly. Finally, the rotor speed is steady at target speed 200 rad/s. The fivephase PMSM is well controlled.

Whenthe flux differential hysteresis is 0.02 ,the a-phase current as shown in Fig.5(a), and when the flux differential hysteresis is 0.06,the a-phase current as shown in Fig.5(b):

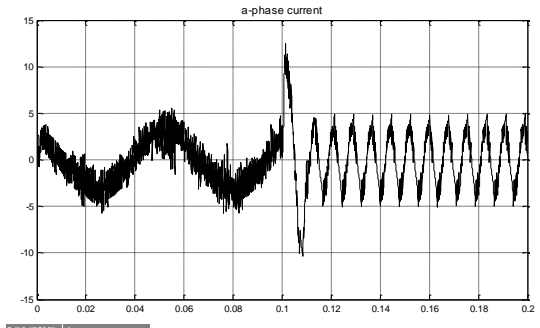

(a)The flux differential hysteresis is 0.02

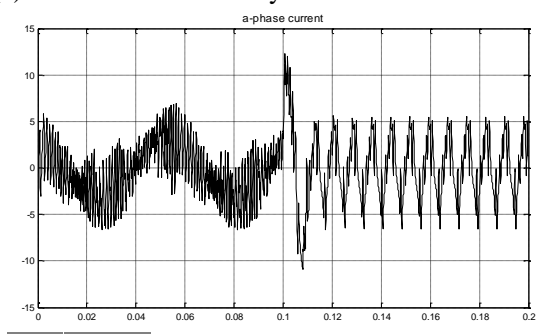

(b)The flux differential hysteresis is 0.06

Fig.5. the image of stator a-phase current

It can be seen that the current ripple is larger in Fig.5(b).The harmonic component of current has a significant increase. And the current has been distorted.

Finally, aimed at motor's high speed operation. Different flux differential hysteresis have different effect on the stator current harmonic. This paper analyze a-phase current in high speed by FFT. It presented in Fig.6, it can be found that Fig.6(b)have lager higher harmonics. It means that larger flux differential hysteresis can cause distortion currents. Although larger flux differential hysteresis can reduce the inverter switching frequency, it will carry more current harmonic, cause the motor heating and reduce the operating efficiency.

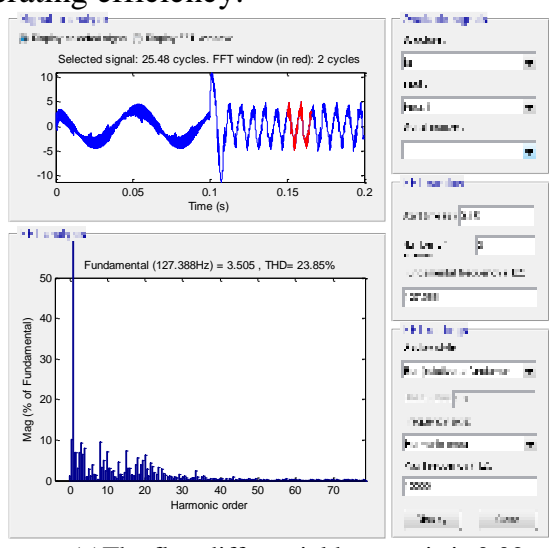

(a)The flux differential hysteresis is 0.02

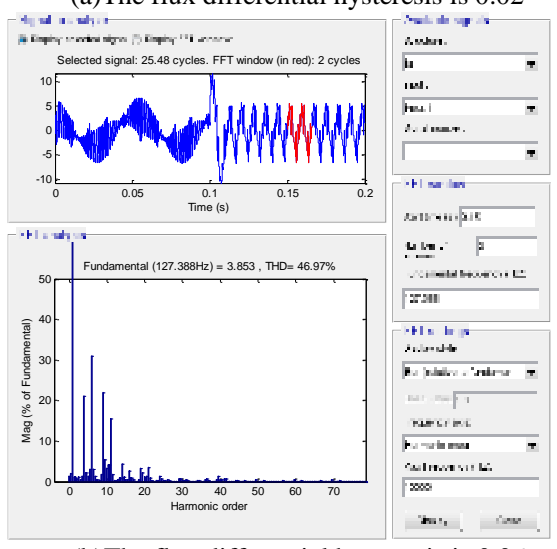

(b)The flux differential hysteresis is 0.06 Fig.6. FFT for a-phase curren

\section{Modified space voltage vector selection table}

It can be seen clearly from above Fig.7 that the torque have large ripples due to the simple selection table. Now the table is modified, and increases five voltage vectors. The specific voltage vectors are presented by the following:

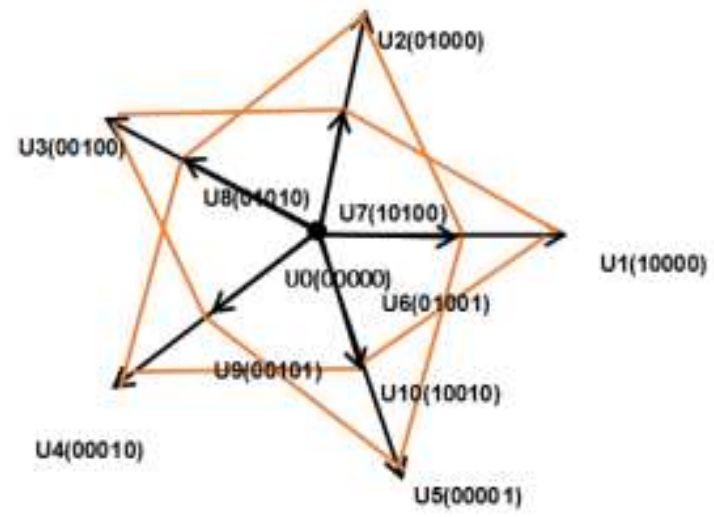

Fig.7. specific voltage vectors

For comparison, this paper uses the same flux differential hysteresis as 0.02 . When the actual amplitude of flux linkage is 0.01 large than the given value, it marks 2 , showed that the amplitude of flux linkage is too big and should adopt large amplitude voltage vectors like U1,U2,U3,U4,U5. When the amplitude is 0.01 smaller than the given value, but lager than 0 ,it marks 1 , showed that the amplitude of flux linkage is relatively large and should adopt small amplitude voltage 
vectors like U6,U7,U8,U9,U10.When the actual value is equal to the given value, it marks 0 and uses the zero vector. So the situations of flux linkage and torque can be divided as follow:

Table4 Situations of flux linkage and torque

\begin{tabular}{|c|c|c|}
\hline code & flux linkage & torque \\
\hline 1 & too big & big \\
\hline 2 & big & big \\
\hline 3 & small & big \\
\hline 4 & too small & big \\
\hline 5 & too big & small \\
\hline 6 & big & small \\
\hline 7 & small & small \\
\hline 8 & too small & small \\
\hline 9 & equal & big \\
\hline 10 & equal & small \\
\hline
\end{tabular}

And the situations of flux linkage and torque are corresponding with marks of flux linkage and torque as follow:

Table.5. Corresponding relation

\begin{tabular}{|l|c|c|c|c|c|c|}
\hline \multicolumn{2}{|c|}{ classification } & \multicolumn{5}{|c|}{ flux linkage } \\
\cline { 2 - 7 } \multicolumn{2}{|l|}{} & -2 & -1 & 0 & 1 & 2 \\
\hline \multirow{2}{*}{ torque } & 1 & 1 & 2 & 9 & 3 & 4 \\
\cline { 2 - 7 } & 2 & 5 & 6 & 10 & 7 & 8 \\
\hline
\end{tabular}

Now, according to the location of sectors, it can choice different voltage vectors as follow:

Table6 Selection of voltage vectors

\begin{tabular}{|l|c|c|c|c|c|c|}
\hline \multicolumn{2}{|l|}{ classification } & \multicolumn{5}{|c|}{ sector location } \\
\cline { 3 - 8 } \multicolumn{2}{|c|}{} & 1 & 2 & 3 & 4 & 5 \\
\hline \multirow{4}{*}{} & 1 & $\mathrm{U} 4$ & $\mathrm{U} 5$ & $\mathrm{U} 1$ & $\mathrm{U} 2$ & $\mathrm{U} 3$ \\
\cline { 2 - 7 } & 2 & $\mathrm{U} 9$ & $\mathrm{U} 10$ & $\mathrm{U} 6$ & $\mathrm{U} 7$ & $\mathrm{U} 8$ \\
\cline { 2 - 7 } & 3 & $\mathrm{U} 10$ & $\mathrm{U} 6$ & $\mathrm{U} 7$ & $\mathrm{U} 8$ & $\mathrm{U} 9$ \\
\cline { 2 - 7 } & 4 & $\mathrm{U} 5$ & $\mathrm{U} 1$ & $\mathrm{U} 2$ & $\mathrm{U} 3$ & $\mathrm{U} 4$ \\
\cline { 2 - 7 } & 5 & $\mathrm{U} 3$ & $\mathrm{U} 4$ & $\mathrm{U} 5$ & $\mathrm{U} 1$ & $\mathrm{U} 2$ \\
\cline { 2 - 7 } & 6 & $\mathrm{U} 8$ & $\mathrm{U} 9$ & $\mathrm{U} 10$ & $\mathrm{U} 6$ & $\mathrm{U} 7$ \\
\cline { 2 - 7 } \\
\cline { 2 - 7 } $\begin{array}{c}\text { situations flux } \\
\text { linkage } \\
\text { and torque }\end{array}$ & 7 & $\mathrm{U} 7$ & $\mathrm{U} 8$ & $\mathrm{U} 9$ & $\mathrm{U} 10$ & $\mathrm{U} 6$ \\
\cline { 2 - 7 } & 8 & $\mathrm{U} 2$ & $\mathrm{U} 3$ & $\mathrm{U} 4$ & $\mathrm{U} 5$ & $\mathrm{U} 1$ \\
\cline { 2 - 7 } & 9 & $\mathrm{U} 0$ & $\mathrm{U} 0$ & $\mathrm{U} 0$ & $\mathrm{U} 0$ & $\mathrm{U} 0$ \\
\hline
\end{tabular}

Fig.8 gives the the overall torque ripples,(a)presents before improvement and (b)presents after improvement.

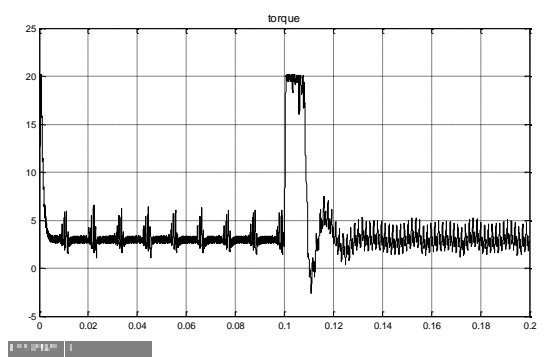

(a)Before improvement

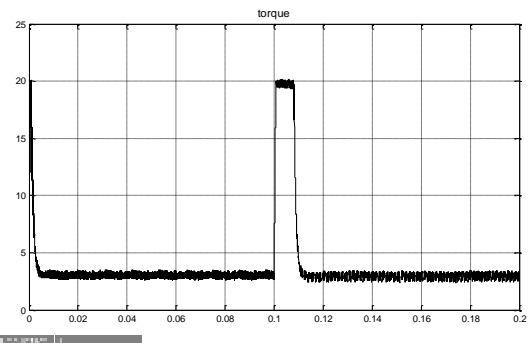

(b)After improvement

Fig.8. the overall torque ripples

Fig.9 gives the steady torque ripples.(a)presents before improvement and (b)presents after improvement.

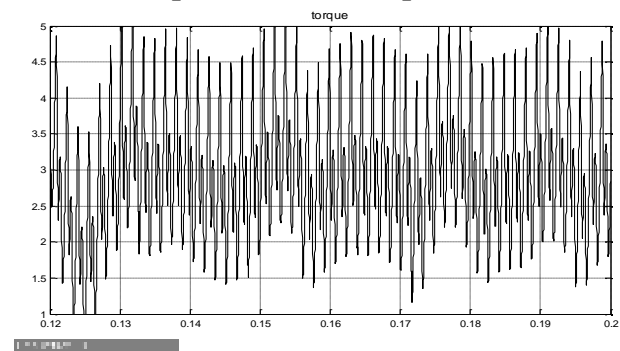

(a)Presents before improvement

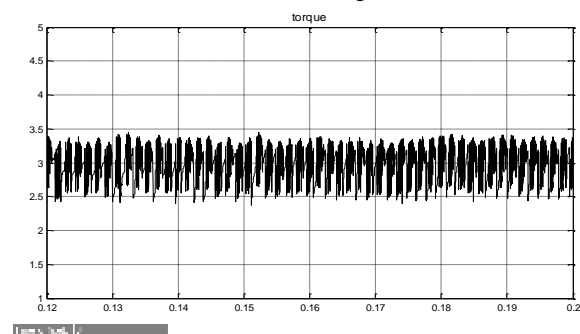

(b)Presents after improvement

Fig.9. The steady torque ripple

From the figures, it can be found that the torque ripples are reduced. So the improvement scheme is correct

\section{CONCLUSIONS}

This paper investigates DTC for five-phase PMSM. The simplified mathematical modeling of five-phase PMSM is given and simulink modeling of five-phase PMSM is presented. The DTC can control the PMSM well, the correctness of the model is verified. Through change the flux differential hysteresis, it can get different profiles of each physical quantity. The larger flux differential hysteresis can cause distortion currents. Although larger flux differential hysteresis can reduce the inverter switching frequency, it will carry more current harmonic

The deficiency of the paper is that the sector division is simple, thus it causes relatively large torque ripples and has 
limited improvement effect. Later works will be aimed at making optimal space voltage vector selection table and weakening the torque ripples.

\section{ACKNOWLEDGMENT}

In this paper, the research was sponsored by key research and development project of Shandong province, China (No. 2016GGX105008). At last, I am very grateful of my dear friend HaoYin, who offered me the confidence and discuss with me about my paper.

\section{REFERENCES}

[1] [1]Yin M,Cong W,LinJ,et al.Optima 1speed controlof PMSMforelectric propulsion based on exact linearization via state feedback[C].Proceedings of the IEEE International Conference on ICIA, 2010:1972-1977.

[2] [2]Xu Y P,Zhong Y R,Yang,H.Research on vector control and direct torque control for permanent magnet synchronous motors[J].Power Electronics.2008,42(1):60-62.

[3] [3]C Rusu ,MM Radulescu ,S Enikö,et al.Embeded Motor Drive Prototype Platform for Testing Control Algorithms[C],International Conference on Applied \& Theoretical Electricity,2014:1-6.
[4] [4] A.L.Gelen,S.Ayasun,Realization of power electronic converter based DC motor speed control methods using MATLAB/Simulink[C],Int.Journal on Engineering Education,2009:33-41.

[5] [5] D Swierczynski ,MP Kazmierkowski.Direct torque control of permanent magnet synchronous motor (PMSM) using space vector modulation (DTC-SVM)-simulation and experimental results[C].Conference of the IEEE Industrial Electronics Society,2002:751-755.

[6] [6] F Korkmaz ,Ísmail Topaloğlu ,MF Çakir .Comparative performance evaluation of FOC and DTC controlled PMSM drives[C].Fourth International Conference on Power Engineering, 2013:705-708

[7] [7] NV Ramana, VLN Sastry.A Novel Speed Control Strategy for Five Phases Permanent Magnet Synchronous Motor with Linear Quadratic Regulator[J].International Journal of Computer and Electrical Engineering,2015,7(6):408-416.

[8] [8] KS Aher,AG Thosar.Modeling and Simulation of Five Phase Induction Motor using MATLAB/Simulink[J].International Journal of Engineering Researchand Applications,2016:01-08.

[9] [9] P Zhao ,G Yang.Torque Density Improvement of Five-Phase PMSM Drive for Electric Vehicles Applications[J].Int Journal of Power Electronics,2011,11(4):401-407. 